\title{
Socio Economic Factors Effecting Immunisation Coverage: Focus Areas.
}

\author{
Vijay Bhaskar Srirangam¹, Maramraj Kiran Kumar², Sandip Mukerji ${ }^{3}$, Rajul Gupta $^{4}$
}

\author{
Vijay Bhaskar $\mathrm{S}^{1}$, Sandip \\ Mukerji' ${ }^{2}$ Rajul Gupta ${ }^{3}$ \\ 'jt Dir Afms (Health), Dg-3a, M-Block, Church Road, \\ New Delhi 110001, INDIA. \\ ${ }^{2}$ SHO, Vishakapatnam, INDIA. \\ ${ }^{3} A F M C$, PUNE, INDIA. \\ ${ }^{4} \mathrm{O} / O$ Dgafms, Ministry of Defence, INDIA.
}

\section{Correspondence \\ Vijay Bhaskar S \\ Jt Dir AFMS (health), DG-3A, M-Block, \\ Church Road, New Delhi 110001, INDIA. \\ Phone no: 7838442656 \\ Email: vijaybhaskar29877@gmail.com \\ History \\ - Submission Date: 08-02-2017; \\ - Revised Date: 01-05-2017. \\ - Accepted Date: 17-07-2017.}

DOI : 10.5530/ijmedph.2017.3.30

\section{Article Available online}

http://www.ijmedph.org/v7/i3

\section{Copyright}

(C) 2017 Phcog.Net. This is an openaccess article distributed under the terms of the Creative Commons Attribution 4.0 International license.

\begin{abstract}
Background: Universal Immunization Programme aims at completing the primary immunization (Bacillus Chalmette-Guérin (BCG), Diphtheria, Pertussis (whooping cough) and Tetanus (DPT)3, Oral polio vaccine (OPV)3, and Measles) for all the children in the country by the time Children become one year old. Despite all the efforts put by governmental as well as non-governmental institutes for $100 \%$ immunization coverage, there are still pockets of low coverage areas existing. Socioeconomic Status (SES) is an important determinant of the standard of living and health status as it influences the incidence and prevalence of various health conditions. Objectives: Aim of the study was to undertake a comparative study of factors associated with Childhood immunisation at a Village and an urban slum in Pune amongst children of preschool age group. The study intended to compare the factors associated with Childhood immunisation at rural and urban areas in children of preschool age group and to find out reasons for non compliance and drop outs of immunisation, if any. Material and Methods: The study was a cross-sectional analytical study. All children in preschool age group (0-60 months) in these areas were included in the study. The mothers/ reliable informants in the family were individually interviewed, using a pre-tested structured questionnaire. A child was categorized as fully immunised, non-immunised, partially immunised and Immunised for Age. Results \& Conclusion: Coverage of vaccines under UIP at urban \& rural communities showed a marked variation. While BCG coverage was $87.7 \%$ \& $79.8 \%$ in the two areas, OPV Zero coverage was $88.7 \% \& 80.8 \%$. Similarly, variation was noted in the coverage of the three doses of OPV/DPT. OPV-1 coverage was $85.8 \%$ \& $72.4 \%$, DPT-1 coverage was $92.2 \%$ \& $71.3 \%$, OPV-2 coverage was $79.9 \%$ \& $78.5 \%$, DPT-2 coverage was $80 \%$ \& $69.4 \%$, OPV-3 coverage was $66.4 \%$ \& 61.5 $\%$, DPT-3 coverage was $64.3 \%$ \& $60 \%$ in urban and rural communities respectively. Measles coverage at urban \& rural community was $72.5 \%$ \& $64.4 \%$. In both urban \& rural communities there was a significant association between Immunisation coverage \& mothers education. In both the communities, the main reason observed was ignorance $35.4 \%$ \& $45.3 \%$ respectively at rural \& urban community. Other common reasons include casual attitude of the parents $(18.5 \%$ in urban area) and sick child (13\% in rural area). Socioeconomic status had a great impact on the immunization coverage in the study. The need of the hour is an equitable, participatory and intersectional approach to health and health care. Provision of vaccination should not be treated as the sole responsibility of the health sector. Convergence, De-centralisation, Community participation and Social inclusion is the need of the hour. Intensive Health education should be undertaken to enhance respondents' knowledge about the complete UIP program and to minimize the gaps regarding the knowledge about correct age of administration, doses, place of vaccination. Evidence-based approach to social mobilisation; develop and provide locally sensitive and appropriate and field-tested IEC resources. Focused efforts to strengthen routine immunization programme especially in the underprivileged groups and areas such as slum in cities so that target of universal coverage can be achieved as envisaged at national level.

Key words: Immunisation, Urban, Rural, Comparative, Dropout.
\end{abstract}

\section{INTRODUCTION}

Children are nature's gift and the fountain of life. They are our future and are a supremely important asset for a nation. The strength of nation lies in the health of citizens. According to the United Nations declaration "the child shall enjoy special protection and shall be given opportunities and facilities by law and order and by means enable him to develop physically and mentally in a healthy and normal manner and in condition of freedom and dignity". Since 1978, the
WHO/UNICEF Expanded Programme on Immunisation has led to steady reductions in childhood mortality from the vaccine preventable diseases both in developed and less-developed nations. Despite all the efforts put by governmental as well as non-governmental institutes for $100 \%$ immunization coverage, there are still pockets of low coverage areas existing in India Wealth-based inequalities in health care provision and utilization are endemic to the developing
Cite this article : Srirangam VB, Kumar MK, Mukerji S, Gupta R. Socio Economic Factors Effecting Immunisation Coverage: Focus Areas. Int J Med Public Health. 2017;7(3):147-51. 
world and India is no exception. ${ }^{1-3}$ A good indicator of accessibility and outreach in the health care sector is the state of childhood immunization. Concerns about equity in health have led to initiatives to collect and analyze data on how health outcomes and services are distributed across social and economic groups. Roughly 3 million children die each year of vaccine preventable diseases (VPDs) with a disproportionate number of these children residing in developing countries. Vaccines remain one of the most cost- effective public health initiatives, yet the cover against VPDs remains far from complete; recent estimates suggest that approximately 34 million children are not completely immunised with almost 98 per cent of them residing in developing countries. India, along with the whole world, stands committed to the welfare of children, as reflected in the theme of 'World Health Day, 2005,' viz., 'Make every mother and child count.' About one-quarter, or $25 \%$, of under- 5 mortality is due to vaccine-preventable diseases. The Expanded Program on Immunisation (EPI) was launched by the WHO and UNICEF in 1974 globally following the eradication of smallpox with focus on prevention of the six childhood vaccine-preventable diseases by the year 2000. In India, immunisation has always been a central goal of the health care system. Despite only fully protecting about half of all infants, infant mortality rate (IMR) has declined during the phasing in of the UIP. IMR continued to decline after 1990. The Child Survival Safe Motherhood (CSSM) and Reproductive Child Health (RCH) programmes started in 1992 and 1997 respectively. Both of these programmes included the UIP as a key component and built upon the infrastructure developed for the UIP. ${ }^{4-9}$

Socioeconomic Status (SES) is an important determinant of the standard of living and health status as it influences the incidence and prevalence of various health conditions. Socioeconomic status also influences social security in terms of the accessibility, affordability, acceptability and actual utilization of various health facilities. Wealth-based inequalities in health care provision and utilization are endemic to the developing world and India is no exception. Although immunisation is but one element of public health services, differential achievements between states, rural/urban areas, and socioeconomic groups give important information about where overall health sector policies. The state of child health in urban slums is comparable to those in rural areas and in some cases even worse. This is especially so in immunisation. ${ }^{10-15}$

In India, discrimination of girls in both preventive (immunisation) and curative (treatment of illness) care are also reported with varying degrees amongst the states. Index of immunisation and school attendance indicate consistent and sharper sex differences suggesting systematic neglect of girls.

\section{Aims and Objectives}

Aim of the study was to undertake a comparative study of factors associated with Childhood immunisation at Village Kasurdi in Pune district and Wanowrie an urban slum in Pune children of preschool age group. The study intended to compare the factors associated with Childhood immunisation at rural and urban areas in children of preschool age group and to find out reasons for non compliance and drop outs of immunisation, if any.

\section{MATERIAL AND METHODS}

The study was an cross-sectional analytical study, conducted at Village Kasurdi \& Wanowrie an Urban slum in Pune, India. The village has an anganwadi which is manned by an anganwadi worker. Wanowrie is an urban slum under the administrative jurisdiction of Pune Cantonment Board (PCB) with population belonging to poor socio-economic strata. All children in preschool age group (0-60 months) in these areas were included in the study. The total population (100\%) of pre-school children (0-60 months) in both these areas were included in the study.
Houses were visited from one direction on each lane/street, taking the house numbers in consideration. The houses visited were marked on the doors and a spot map was also prepared for the area and houses to avoid duplication of data collected from an individual house. In case of a locked house, it was ensured that the house was marked with red in the spot map and was visited later to cover the missed children. A total of 136 children who fulfilled all the criteria required for the study were present in the rural community and all of them were included in the study. At Urban slum a total of 116 children fulfilled the criteria.

The mothers/ reliable informants in the family were individually interviewed, using a pre-tested structured questionnaire. The Questionnaire (schedule) included questions about household identification data, educational status and occupation of the parents, income of the family, utilization of child health services and reasons for non-utilization if any. Immunization coverage was ascertained from information on immunization cards, where these were available, and mother's report where these cards were not available. Age was recorded to the nearest completed months after verifying birth certificates, Aanganwadi registers and informants memory as correlated with any special event or a festival. The Socio economic scales employed in the study was Kuppuswamy's socioeconomic status scale. The scale incorporates three characteristics to be assessed and scored: Education level of the head of family (HOF), occupation of the HOF, and income per month. Each variable is given scoring and based on the rating the socioeconomic scales are categorized into various classes. The living siblings were taken into consideration for the birth order of living children.

A child was categorized as fully immunised if that child has received one dose of BCG, three doses each of DPT and OPV and one dose of measles vaccine by the time of the survey. Child was categorized as non-immunised if that child has received none of these vaccines by the time of the survey. Child was categorized as partially immunised if he has received at least one immunization but has not completed the immunization as per fully immunised status. The study has taken a fourth category as Immunised for Age for those children who have received immunization as per their present age but has not yet completed the entire immunization schedule. The reason for taking this category into consideration was that even if they were immunised for age they might still default in immunization due to various reasons in coming years. During analysis the four Immunisation coverage groups were clubbed into two groups. The fully immunised for age were included as immunisation appropriate whereas Partial \& Non immunised children were grouped as Immunisation default.

All children of migrant population visiting their friends and relatives residing in these areas and Children not born in the village Kasurdi and Wanowrie Bazaar were excluded from the study.

\section{RESULTS}

\section{Demographic Profile of Urban and Rural Community}

The age-wise distribution of children showed that in rural community $28 \%$ children were in age group 31 - 40 months and at urban community the predominance was in age groups $10-30$ months. Both the population showed predominance of male child. $65.45 \%$ children in rural and $60.3 \%$ in urban communities were male. The distribution as per birth order showed that in rural community $45.6 \%$ were in birth order 2 and in urban community $49 \%$ were of birth order 1 . (Table 1 ). The educational status of mothers showed that $12.5 \%$ women in rural \& $4.3 \%$ in urban community were uneducated. Only $21.3 \%$ women in rural community had education of $10 y r s \&$ above. In rural area the major occupation was found to be farming (30.9\%) followed by unskilled workers, whereas in urban area skilled workers were predominant (37.1\%) . 52\% children in 
rural community belonged to SES class IV i.e. upper lower class. At urban community $56 \%$ belonged to this class. Children in Lower SES class (class IV) were higher at rural community (10.3\%) as compared to $4.3 \%$ in urban community. (Table 2)

\section{Comparative analysis of Immunisation coverage}

The Immunisation coverage at Urban community showed that $65.5 \%$ children were fully immunised whereas same at rural community it was $44.9 \%$. The children who were partially immunised were $29.3 \%$ \& 41.9 $\%$ in urban \& rural community. $2.6 \%$ children in urban community have not been immunised at all \& the same rural community it was $11 \%$. There was clear correlation between Immunisation coverage \& domicile, which was statistically significant. (Table 3 )

\section{Coverage of vaccines under UIP at urban \& rural communities}

Coverage of vaccines under UIP at urban \& rural communities showed a marked variation. While BCG coverage was $87.7 \%$ \& $79.8 \%$ in the two areas, OPV Zero coverage was $88.7 \%$ \& $80.8 \%$. Similarly, variation was noted in the coverage of the three doses of OPV/DPT. OPV-1 coverage was $85.8 \%$ \& $72.4 \%$, DPT- 1 coverage was $92.2 \%$ \& $71.3 \%$, OPV-2 coverage was $79.9 \% \& 78.5 \%$, DPT-2 coverage was $80 \% \& 69.4 \%$, OPV-3 coverage was $66.4 \%$ \& $61.5 \%$, DPT-3 coverage was $64.3 \%$ \& $60 \%$ in urban and rural communities respectively. Measles coverage at urban \& rural community was $72.5 \%$ \& $64.4 \%$. Booster dose coverage showed mild variation. While DPT- 4 coverage was $60.1 \%$ \& $54 \%$ in urban and rural areas, DT coverage was $62.1 \%$ \& $56.2 \%$ respectively.

\section{Gender differential in Immunisation coverage}

In Urban community, male children appropriately immunised were $70 \%$ whereas the same for females was $65.2 \%$. In rural community, however, the difference is more marked, with $60.7 \%$ male children appropriately immunised, as against only $25.5 \%$ female children. The difference among genders in rural area was statistically significant. (Table 4)

\section{Birth order and Immunisation coverage}

While in urban community $84.6 \%$ of children of birth order $>2$ were appropriately immunised, only $15.8 \%$ of these children in rural area received appropriate immunisation. This was a statistically significant finding (Table 5).

\section{Mother's Literacy and Immunisation Coverage}

In both urban \& rural communities there was a significant association between Immunisation coverage \& mothers education. As the mother's education increased the immunization coverage also improved. (Table 6)

\section{Source of information and Immunisation Coverage}

At both the communities the main source of information was the doctors. At rural community, Anganwadi worker (AWW) played a significant role in providing information to the mothers about the immunization. (Table 7)

\section{Reasons for partial Immunisation / Reasons for Non Immunisation of the child}

In both the communities, the main reason observed was ignorance $35.4 \%$ \& $45.3 \%$ respectively at rural \& urban community. Other common reasons include casual attitude of the parents (18.5\% in urban area) and sick child (13\% in rural area). (Table 8 )

\section{Additional findings}

Though a considerable number of respondents had satisfactory knowledge about the Universal immunization programme, respondents' inability to name or identify diseases other than tuberculosis and poliomyelitis was evident at both the communities. There exists a wide gap in the knowledge regarding correct age of administration, doses, place of vaccination. A well established primary health care setup was seen at rural community but no such provision at urban community. The most of medical care was clinic oriented and no urban health post was established in the community or in vicinity for the residents. As most of them were from a low SES \& involved in unorganized work sectors, not many were availing the facilities of health insurances.

\section{DISCUSSION}

Rural urban difference in immunization coverage has been significant in most of the studies, with favourable outcome in urban areas as compared to rural. The dropout rate for DPT and OPV was also less in urban and semi-urban than in the rural areas. Gender differential was significant in the rural community. A number of studies have drawn attention to the problem of discrimination against the female child. They have shown that immunization coverage of female children is lower than males. Children with birth order $<2$ had a positive association in having better immunisation coverage as compared to a child with birth order $>2$.

Various studies have shown the relation of birth order with immunization coverage. The levels of immunization coverage were better in lower birth order as compared to the higher birth orders. There was a significant association between immunisation coverage \& mothers education. As the mother's education increased the immunization coverage also improved. As Per NFHS - 3, percentage of children fully immunised born to mothers with no education was only $26.1 \%$ as compared to $71 \%$ in mothers with education 10yrs \& above. Same for BCG was $64.7 \%$ \& $96.55 \%$, for Measles it was $41 \%$ \& $86 \%$. Education of women was directly related to the fertility pattern and also to other child-health indicators. Mother's education has shown important influence over child health care choices related to immunisation. This positive effect is purely driven by the knowledge and awareness associated with maternal education.

\begin{tabular}{ccccccc}
\multicolumn{7}{c}{ Table 1: Children as per Birth order } \\
\multicolumn{7}{c}{} \\
$\mathbf{1}$ & $\mathbf{2}$ & $\mathbf{3}$ & $\mathbf{4}$ & $\mathbf{5}$ & TOTAL \\
Rural & 55 & 62 & 14 & 5 & 0 & 136 \\
$(\%)$ & $(40.4)$ & $(45.6)$ & $(10.3)$ & $(3.7)$ & $(0.0)$ & $(100.0)$ \\
Urban & 57 & 46 & 9 & 3 & 1 & 116 \\
$(\%)$ & $(49.1)$ & $(39.7)$ & $(7.8)$ & $(2.6)$ & $(0.9)$ & $(100.0)$ \\
TOTAL & 112 & 108 & 23 & 8 & 1 & 252 \\
$(\%)$ & $(44.4)$ & $(42.9)$ & $(9.1)$ & $(3.2)$ & $(0.4)$ & $(100.0)$
\end{tabular}

\begin{tabular}{cccccc}
\multicolumn{5}{c}{ Table 2: Urban- Rural distribution as per SES } \\
U/R & Lower (V) & $\begin{array}{c}\text { Upper } \\
\text { Lower } \\
\text { (IV) }\end{array}$ & $\begin{array}{c}\text { Lower } \\
\text { Middle(III) }\end{array}$ & $\begin{array}{c}\text { Upper } \\
\text { Middle } \\
\text { (II) }\end{array}$ & TOTAL \\
\hline Rural & 14 & 72 & 46 & 4 & 136 \\
$(\%)$ & $(10.3)$ & $(52.9)$ & $(33.8)$ & $(2.9)$ & $(100.0)$ \\
Urban & 5 & 65 & 41 & 5 & 116 \\
$(\%)$ & $(4.3)$ & $(56.0)$ & $(35.3)$ & $(4.3)$ & $(100.0)$ \\
TOTAL & 19 & 137 & 87 & 9 & 252 \\
$(\%)$ & $(7.5)$ & $(54.4)$ & $(34.5)$ & $(3.6)$ & $(100.0)$ \\
\hline
\end{tabular}

Comparative analysis of Immunisation coverage 


\begin{tabular}{cccccc}
\multicolumn{5}{c}{ Table 3: Urban Rural Differences in Immunisation Coverage } \\
& $\begin{array}{c}\text { Fully } \\
\text { Immunised }\end{array}$ & $\begin{array}{c}\text { Immunised } \\
\text { for Age }\end{array}$ & $\begin{array}{c}\text { Not } \\
\text { immunised }\end{array}$ & $\begin{array}{c}\text { Partially } \\
\text { immunised }\end{array}$ & TOTAL \\
$\begin{array}{c}\text { Urban } \\
(\%)\end{array}$ & 76 & 3 & 3 & 34 & 116 \\
& $(65.5)$ & $(2.6)$ & $(2.6)$ & $(29.3)$ & $(100.0)$ \\
$\begin{array}{c}\text { Rural } \\
(\%)\end{array}$ & 61 & 3 & 15 & 57 & 136 \\
& $(44.9)$ & $(2.2)$ & $(11.0)$ & $(41.9)$ & $(100.0)$ \\
$\begin{array}{c}\text { TOTAL } \\
(\%)\end{array}$ & 137 & 6 & & & \\
& $(54.4)$ & $(2.4)$ & $(7.1)$ & $(36.1)$ & $(100.0)$ \\
\end{tabular}

Chi square: $1021.9 ;$ df: $3 ; \mathrm{p}<0.05$

\begin{tabular}{|c|c|c|c|c|c|c|}
\hline \multirow{2}{*}{$\begin{array}{c}\text { Immunisation } \\
\text { Coverage }\end{array}$} & \multicolumn{3}{|c|}{ Urban } & \multicolumn{3}{|c|}{ Rural } \\
\hline & $<2$ & $>2$ & Total & $<2$ & $>2$ & Total \\
\hline $\begin{array}{c}\text { Immunisation } \\
\text { Appropriate } \\
(\%)\end{array}$ & $\begin{array}{c}68 \\
(66.0)\end{array}$ & $\begin{array}{c}11 \\
(84.6)\end{array}$ & $\begin{array}{c}79 \\
(68.1)\end{array}$ & $\begin{array}{c}63 \\
(53.8)\end{array}$ & $\begin{array}{c}03 \\
(15.8)\end{array}$ & $\begin{array}{c}66 \\
(48.5)\end{array}$ \\
\hline $\begin{array}{l}\text { Immunisation } \\
\text { Default } \\
(\%)\end{array}$ & $\begin{array}{c}35 \\
(34.0)\end{array}$ & $\begin{array}{c}02 \\
(15.4)\end{array}$ & $\begin{array}{c}37 \\
(31.9)\end{array}$ & $\begin{array}{c}54 \\
(46.2)\end{array}$ & $\begin{array}{c}16 \\
(84.2)\end{array}$ & $\begin{array}{c}70 \\
(51.5)\end{array}$ \\
\hline $\begin{array}{c}\text { Total } \\
(\%)\end{array}$ & $\begin{array}{c}103 \\
(100.0)\end{array}$ & $\begin{array}{c}13 \\
(100.0)\end{array}$ & $\begin{array}{c}116 \\
(100.0)\end{array}$ & $\begin{array}{c}117 \\
(100.0)\end{array}$ & $\begin{array}{c}19 \\
(100.0)\end{array}$ & $\begin{array}{c}136 \\
(100.0)\end{array}$ \\
\hline
\end{tabular}

$\begin{array}{cccc}\text { Table 4: Gender differential in Immunisation coverage } & \\ \text { Sex } & \begin{array}{c}\text { Immunisation } \\ \text { Appropriate }\end{array} & \begin{array}{c}\text { Immunisation } \\ \text { Default }\end{array} & \text { TOTAL } \\ \text { Male } & 54 & 35 & 89 \\ (\%) & (60.7) & (39.3) & (100.0) \\ \text { Female } & 12 & 35 & 47 \\ (\%) & (25.5) & (74.5) & (100.0) \\ \text { Total } & 66 & 70 & 136 \\ (\%) & (48.5) & (51.5) & (100.0)\end{array}$

Chi square: 13.83 ; df: $1 ; \mathrm{p}<0.05$

\begin{tabular}{|c|c|c|c|}
\hline \multicolumn{4}{|c|}{$\begin{array}{l}\text { Table 6: Correlation of Mother's Literacy \& Immunis } \\
\text { urban community. } \\
\qquad \text { Immunisation Coverage Group }\end{array}$} \\
\hline Mothers Edn & $\begin{array}{l}\text { Immunisation } \\
\text { Appropriate }\end{array}$ & $\begin{array}{l}\text { Immunisation } \\
\text { Default }\end{array}$ & Total \\
\hline 10 yrs \& above (\%) & $39(72.2)$ & $15(27.8)$ & $54(100.0)$ \\
\hline $8-9$ yrs (\%) & $16(80.0)$ & $4(20.0)$ & $20(100.0)$ \\
\hline$<8$ yrs $(\%)$ & $22(59.5)$ & $15(40.5)$ & $37(100.0)$ \\
\hline No Education (\%) & $2(40.0)$ & $3(60.0)$ & $5(100.0)$ \\
\hline Total (\%) & $79(68.1)$ & 37 (31.9) & $116(100.0)$ \\
\hline
\end{tabular}

Chi square: 468.8 ; df: 3; $\mathrm{p}<0.05$

\begin{tabular}{|cccccccccc}
\hline \multicolumn{2}{l}{ Table 7: Source of information and Immunisation Coverage } \\
& AWW & $\begin{array}{c}\text { Comm } \\
\text { leaders }\end{array}$ & Doctors & Media & MSW & Paramed & Family & NIL & Total \\
\hline Urban (\%) & $0(0.0)$ & $04(3.4)$ & $59(50.9)$ & $14(12.1)$ & $18(15.5)$ & $09(7.8)$ & $08(6.9)$ & $04(3.4)$ & $116(100.0)$ \\
Rural (\%) & $31(22.8)$ & $02(1.5)$ & $49(36.0)$ & $04(2.9)$ & $11(8.1)$ & $13(9.6)$ & $21(15)$ & $05(3.7)$ & $136(100.0)$ \\
TOTAL (\%) & $31(12.3)$ & $06(2.4)$ & $108(42.9)$ & $18(7.1)$ & $29(11.5)$ & $22(8.7)$ & $29(11)$ & $09(3.6)$ & $252(100.0)$
\end{tabular}

At both the communities the immunization coverage significantly increased as per SES. The main reason observed was ignorance, which was $35.4 \%$ \& $45.3 \%$ respectively at rural \& urban community. Other common reasons include casual attitude of the parents (18.5\% in urban area) and sick child (13\% in rural area). Various studies over the years have suggested a number of causes of low immunisation coverage.

Universal immunization programme to begin with was introduced in every district of the country, and the target was to achieve $100 \%$ immunization coverage although technically $85 \%$ coverage levels would ensure herd immunity. Vaccination coverage determines the herd immunity being developed in the community to prevent any outbreaks. The immunization coverage found in the rural and urban slum was way below the expected goals and the development of herd immunity in these locations is a question mark. This reiterates the fact that the coverage has to be improved and herd immunity needs to be developed to ensure effective vaccination and prevent vaccine preventable diseases.
A well established primary health care setup is seen at rural community but no such provisions exist on ground at urban communities. The most of medical care is clinic oriented. The recommendations for urban communities to have urban health post still are far from implementation in the area. Is no uniform set of norms for urban health posts? In rural areas, an ANM/AWW visits the village and provides community-based services. This is not true for urban slums. Women have to go to a hospital or dispensary to avail of basic services such as immunisation of their children or antenatal care during pregnancy. As a result the urban poor have to spend time and money in travel to the hospital/dispensary to avail of services. There exists no uniform set of norms for urban health posts. In rural areas, an ANM/AWW visits the village and provides community-based services. This is not true for urban slums. Women have to go to a hospital or dispensary to avail of basic services such as immunisation of their children or antenatal care during pregnancy. 


\begin{tabular}{|c|c|c|}
\hline & Rural (\%) & Urban (\%) \\
\hline Ignorance & 22.4 & 29.2 \\
\hline Unaware of need for immunisation & 13 & 16.1 \\
\hline $\begin{array}{l}\text { Unaware of need to return for } 2 \text { nd and } 3 \text { rd } \\
\text { dose }\end{array}$ & 8.3 & 7.1 \\
\hline Fear of side effects & 4.7 & 2.4 \\
\hline Fear that vaccine would cause the disease & 3.5 & 7.1 \\
\hline Place and time unknown & 2.8 & 3.6 \\
\hline Casual attitude & 9.4 & 18.5 \\
\hline No faith in immunisation & 2 & 1.8 \\
\hline Rumours & 0.8 & 0 \\
\hline Distance from health center & 0.8 & 0 \\
\hline Sick Child & 17.7 & 8.9 \\
\hline Non availability of vaccines & 1.6 & 1.2 \\
\hline Non availability of health care worker & 1.6 & 0 \\
\hline Influence of family and others & 4.3 & 0 \\
\hline Gender discrimination & 1.6 & 1.8 \\
\hline Migration & 3.1 & 0.6 \\
\hline Negative attitude & 1.2 & 0.6 \\
\hline Scarcity of time & 1.2 & 1.2 \\
\hline
\end{tabular}

\section{CONCLUSION}

It is a well known fact that immunization is higher for children from urban areas as compared to the rural communities but a striking feature which appeared in the study was that the urban slums who belong to the under-privileged lot in the cities are equally affected and the immunization coverage in this area, though marginally higher than the rural community, still lags to a greater extent. Health education and behavior change communication is an important tool for effective coverage and utilization of health resources. ${ }^{16,17}$ The socioeconomic status which also encompasses the financial condition of the family has a major role in coverage. The lack of knowledge about the immunization drives being organized for free by government at times leads to draining of meager finances by the family on immunization of the child. This inturn at times leads to incomplete, partial or nil immunization in these communities. The need of the hour is an equitable, participatory and intersectional approach to health and health care. Provision of vaccination should not be treated as the sole responsibility of the health sector. Convergence, De-centralisation, Community participation and Social inclusion is the need of the hour. Intensive Health education should be undertaken to enhance respondents' knowledge about the complete UIP program and to minimize the gaps regarding the knowledge about correct age of administration, doses, place of vaccination.

Evidence-based approach to social mobilisation; develop and provide locally sensitive and appropriate and field-tested IEC resources. Focused efforts to strengthen routine immunization programme especially in the underprivileged groups and areas such as slum in cities so that target of universal coverage can be achieved as envisaged at national level.

\section{ACKNOWLEDGEMENT}

NIL.

\section{CONFLICT OF INTEREST}

There are no conflicts of interest .

\section{REFERENCES}

1. Vaccines and Biologicals - WHO vaccine preventable diseases monitoring system 2002 global summary. World Health Organization pp 121 - Immunization profile -INDIA 2002

2. National Review of Immunization Programme in India, NIHFW, New Delhi: 1989.

3. Family Health Survey (NFHS-2) key findings, International Institute of Population sciences. $1998-99 ; 135$.

4. Report of the working groups on Registration of births, deaths and marriages. NCP, Govt. of India, 2001.

5. Sokhey J, Mathur YN, Biellik R. Country overview--a report of the international evaluation of the immunization programme in India. Indian pediatrics. $1993 \mathrm{Feb}$ $1 ; 30(2): 153-74$.

6. Government of India. National Child Survival and Safe motherhood programme, New Delhi. Department of Family Welfare, 1994.113.

7. Sunder Lal, B.M. Vashisht. Innovative approaches to universalize immunization in rural area Indian journal of community medicine vol. 28, 2003.

8. National Mission on Immunization. Dept, of Family Welfare MOH\&FW, Dept, of Biotechnology Government of India New Delhi. 1988.

9. National Family Health Survey-2, India. Child Morbidity and Treatment. Mumbai : Indian Institute of Population Sciences 1998-1999;217.

10. Manual on community needs assessment approach (formerly target free approach) in Family Welfare Programme. Department of Family Welfare, MOH\&FW, GOI, 1998.

11. Health Population and Family Welfare Statistics. Collection of Current Statistics from Journals received in 1999, New Delhi, National Family Welfare Institute, 1999.

12. National Population Policy 2000, Dept, of Family Welfare, MOKFW, GOI, Nirman Bhawan, New Delhi.

13. Multi-year plan for UIP 2005-2010. UIP Guiding principles to achieve its mission Ministry of Health and Family Welfare, Government of India.

14. Global Alliance for Vaccines and Immunization (GAVI) and The Vaccine Fund GOI proposal document.

15. National Family Health Survey (NFHS-3), International Institute of Population sciences, Deonar Mumbai, 2005.

16. Luthar S. Immunizing more children: Towards greater community participation. UNICEF, Regional Office for South Central Asia, New Delhi. 1984.

17. Racine AD, Joyce TJ. Maternal education, child immunizations, and public policy: evidence from the US National Immunization Survey. Social science \& medicine. 2007:65(8):1765-72 